\title{
Measuring learning quality by Moroccan university students
}

Fatima Zahra Soubh*

$\mathrm{B}$

Mohammed Aitdaoud

B

Laurent Lima

Mohammed Talbi

B

Suggested Citation:

International Journal of Learning and Teaching. 9

Q

M

Q $\quad s \quad$ B

Abstract

V

V

v

B

Q QB QQ M MB Fatima Zahra Soubh,

E-mail address: 
1. Introduction

M

Evaluation of education quality 


\section{Method}

\subsection{Participants}

F

2.2. Measures

2.3. Procedure

M

2.4 .

3. Assessment made on characteristics and dimensions of the process education / training

B

Q

V

Q 


\section{On facing good or bad situations in education}

Q

B

B 
Q

Q

Q

Q

Q

Q

V

understandable and relevant courses

teachers ensure

that the course is understood provide examples

interesting and motivating teachers

teachers

educational objectives clearly defined teachers provide summaries

The teachers ensure that the course is

V

interesting and motivating teachers 
Q

Q

Q

Q

Q

Q

$\mathrm{V}$

what will be the subject of the review

relationships with other disciplines

explanation of

the practical interest of the subjects demonstrated

the application of research methods

$\mathrm{V}$

will be the subject of the review

explanation of what

understood

clearly defined educational objectives

teachers ensure that the course is

understandable and relevant

V

being

motivating teachers

\section{Personal progressions recorded}

B 


\begin{tabular}{ll}
\hline $\mathrm{F}$ \\
$\mathrm{B}$
\end{tabular}

V

\section{Discussion}

V

Acknowledgements 


\section{References}

B

B

B

Q M
B

B 